\title{
Increasing Patient Motivation and Adherence to Nutritional Care: The Importance to Overcome Psychological Barriers
}

\author{
Maria Eduarda Batista de Lima and Stefano Eleuteri
}

\begin{abstract}
Eating habits are inseparably linked with people's physical and psychological health and well-being. Many factors impact on eating behavior and nutritional status in older adults. Motivational and multidisciplinary interventions have been shown to be highly effective in promoting healthy eating, especially in hospitalized patients, but are often overlooked or not considered. The aim of this chapter is to discuss how to overcome the psychological barriers that lead older patients away from an appropriate nutritional intake and the importance of motivational interventions for adherence to nutritional care, providing useful evidence and direction for further research.
\end{abstract}

\section{Keywords}

Motivational interventions $\cdot$ Nutritional care adherence $\cdot$ Older adults $\cdot$ Motivation - Nutritional therapy

This chapter is a component of Part I: Nutritional Care in Old Age.

For an explanation of the grouping of chapters in this book, please see Chap. 1: "Overview of Nutrition Care in Geriatrics and Orthogeriatrics."

M. E. Batista de Lima $(\bowtie)$

Education Committee, Fragility Fracture Network, NHS South East Tuscany, Siena, Italy

S. Eleuteri

Education Committee, Fragility Fracture Network, Sapienza University of Rome, Rome, Italy e-mail: stefano.eleuteri@uniroma1.it

Ó. G. Geirsdóttir, J. J. Bell (eds.), Interdisciplinary Nutritional Management and 


\section{Learning Outcomes}

By the end of this chapter, you will be able to:

- Recognize the complexities of diverse psychological barriers and enablers to nutritional care in older adults.

- Share understanding regarding older adults' perspectives regarding the relationship between food and nutritional care.

- Describe opportunities to improve the role of caregivers and the community in supporting patient motivation and adherence to nutritional care.

- Explain the rationale and benefit of interdisciplinary teams in supporting positive nutrition-related behavior change in older adults.

\subsection{Introduction}

The nutritional status of older frail and hospitalized patients has been shown to be of high importance for general well-being and for their recovery. Patients at risk of malnutrition are known to have increased rates of infections and mortality. Nutritional risk also seems important for the degree of health and strength that patients recover after hospitalization $[1,2]$.

During the last years, guidelines have been developed to ensure the right care for patients at nutritional risk during hospitalization [3]. These guidelines consider screening for nutritional risk, nutrition plan, and monitoring as well as communication to other healthcare providers, when the patient still needs nutritional assistance at transferal between hospital departments or at discharge. A concrete division of tasks within the nutrition process has been shown important for good nutritional practice. Nurses play a significant role in nutritional care $[4,5]$.

Evidence suggests that approximately $30 \%$ of patients with nutritional risk are in hospitals, although estimates vary with differences in populations. More than half of these patients have a daily energy and protein intake of less than $75 \%$ of their needs, and up to $40 \%$ lose weight during hospitalization $[6,7]$. The reasons for this insufficient food intake are multiple and complex. Insufficient knowledge of hospital staff about nutritional needs and a lack of attention to nutritional problems, especially among nurses, has been described [2, 7-10].

Some clinical controlled trials between specific patient groups have shown that active patient involvement in their own nutritional care and mentoring of patients could increase the patient's energy intake $[8,10]$. This is underlined by surveys which point out that patients have quite concrete expectations about their nutritional care, but do not seem to express them to staff $[7,8]$.

Of all older adults admitted to the acute setting, orthopedic patients have been shown to be among those most severely undernourished. The attention to nutritional aspects as part of patient care is undervalued and underdeveloped [11]. Creating strategies within which effective nutritional treatment can be achieved is vital. Effective management of nutrition for those at risk will speed recovery and reduce the incidence of secondary complications and mortality, reducing nursing workload in both hospitals and community settings [12]. 
Traditionally, nutrition has been a nursing responsibility, as caring for the patients' basic needs [13]. Today, nutrition is an interdisciplinary field shared across several professions. Interdisciplinary and multimodal nutritional assistance facilitates the exploration of the barriers presented by the patient that prevent receipt of quality nutrition. The involvement of healthcare providers helps to identify these barriers and implement targeted practical and motivational solutions, offering a greater proportional increase in protein and energy intake and improved patientreported experience measures $[12,14-16]$.

\subsection{The Relationship Between Older Adults and Food as a First Step Toward Overcoming Psychological Barriers}

Many studies demonstrate that food preferences in older adults take into consideration how people's experiences change with aging: changes in taste, diet, and food choice. Primarily, this occurs when most people approach the age of 70 or older. Influencing variables can include social and cultural environment, gender, and personal habits as well as physical and mental health. Scientific studies attempting to explain why people like or dislike certain foods have been performed to deepen understanding of these issues [17-19].

Research is continuously examining the variables that cause older adults to change food preferences, one example being the Elderly Nutrition Program (ENP). To improve the quality of meal programs, the ENP explored how food preferences varied depending on biological sex and ethnic groups. A total of 2024 participants aged 60 years or older were interviewed. Most of the participants were female, served by congregate meal programs, or meals served in community settings such as senior centers, churches, or senior housing communities [20].

A general impression of the meals and preferences for 13 food groups (fresh fruit, chicken, soup, salad, vegetables, potatoes, meat, sandwiches, pasta, canned fruit, legumes, deli meats, and ethnic foods) was assessed. In addition, compared with African Americans, the study found that Caucasians demonstrated higher percentages of preference for 9 of 13 food groups, including pasta, meat, and fresh fruit, and recommended that to improve the quality of the ENP and to increase dietary compliance of the older adults to the programs, the nutritional services require a strategic meal plan that solicits and incorporates older adults' food preferences $[20,21]$.

There are multiple factors in an older adult's life that can affect food preferences. Aspects like the environment, mental and physical health medications, food access, and lifestyle choices can all contribute to the individual taste and/or habits. It has been long recognized that the nutritional status of older adults relates to their quality of life, ability to live independently, and their risk for developing costly chronic illnesses [22]. An aging adult's nutritional well-being can be affected by multiple socio-environmental factors, including access to healthy and affordable foods, congregate meal sites, and nutritious selections at restaurants. The Academy of Nutrition and Dietetics, the American Society for Parenteral and Enteral Nutrition (ASPEN), 
and the Society for Nutrition Education and Behavior have identified an older adult's access to a balanced diet to be critical for the prevention of disease and promotion of nutritional wellness so that quality of life and independence can be maintained throughout the aging process and excessive healthcare costs can be reduced $[3,23]$.

\subsubsection{Age: Younger and Older Adults}

As people age, their bodies change. This can include their taste buds, their needs of certain vitamins and nutrients, and their desire for different types of food. A study was performed with the participation of 50 young adults and 48 older adults [24]. "Young" subjects ranged from 18 to 35 years of age and "older" subjects were defined as 65 years of age or older. There were more females than males in the study, but there were approximately equal proportions of males and females in the two age groups. The study observed that younger females had stronger cravings for sweets than older females. Causation theories included accounting this difference in preference with the younger female test subject's menstrual cycles and the fact that older women no longer go through menopause. The study also postulated that $91 \%$ of the cycle-associated cravings were said to occur in the second half of the cycle (between ovulation and the start of menstruation). These physical changes can be considered when assessing why someone of an older age might not be getting the nutrition they need. As taste buds change with age, certain foods might not be seen as appetizing, for example, the suggestion that as we age, our sense for tasting salty foods goes away slowly [25].

\subsubsection{Biological Sex: Older Male and Female}

Food preferences also differ among biological sexes. A study demonstrated that older males were "significantly more likely to prefer deli meats, meat, legumes, canned fruit, and ethnic foods compared to females" [13, 14]. Another research concluded that females had significantly more cravings for sweets and for chocolate than males; and the study results suggested that males had more cravings or preferences for savory foods than sweets [24].

\subsubsection{Personal Health}

\subsubsection{Physical Health}

With age, some people tend to avoid food or are unwilling to modify their diets due to oral health problems. These issues, such as ill-fitting dentures (false teeth) or gum disease, are associated with significant differences in dietary quality, which is a measure of the quality of the diet using a total of eight recommendations regarding the consumption of foods and nutrients from the National Academy of Sciences 
(NAS). Approaches to minimize food avoidance and promote changes to the diets of people that have eating difficulties due to oral health conditions are needed desperately because without being able to chew or take in food properly, their health is affected drastically, and their food preferences are limited greatly (to soft or liquids only) [26] (Chap. 18).

Due to varying factors of older adults' physical and mental well-being, eating choices can become more and more restricted. Many older adults are constrained into eating softer foods, foods that incorporate fiber and protein, drinking calciumpacked liquids, and so on. Six of the leading causes of death for older adults, including cardiovascular disease, cancer, chronic lower respiratory disease, stroke, Alzheimer's, and diabetes mellitus, have nutrition-related causes and/or respond favorably to nutritional interventions. These six illnesses can implement certain restrictions and heavily influence the diet [27].

Declining physical health (e.g., patients with arthritis) can also cause dietary deterioration due to difficulties in food purchasing, preparation, and consumption [26].

Some authors noted that old adults are less active and have lower metabolism with a consequent lower need to eat. In addition, they tend to have existing diseases and/or take medications that interfere with nutrient absorption. Based on their research dietary requirements, one study developed specific recommendations for adults over 70 [28].

\subsubsection{Mental Health}

The impact of certain diseases can also impact the quality of nutritional intake in the old population, especially those that are in care facilities. Certain risk factors include conditions that impair cognitive function, such as dementia [29].

As a result of certain mental health conditions and/or diseases-like Alzheimer's and Parkinson's disease-a person's food preferences might become affected. Since the experience of flavor is significantly altered, people with dementia can often change their eating habits and take on entirely new food preferences. In this study, the researchers found that these dementia patients had trouble identifying flavors and appeared to have lost the ability to remember tastes, therefore leading to a theory that dementia caused the patients to lose their knowledge of flavors [30].

Psychological conditions can also affect eating habits. For instance, length of widowhood may affect nutrition [31]. Depression in old people is also associated with a risk of malnutrition $[29,31]$.

\subsubsection{Lifestyle Choices}

Old adults have different lifestyle choices involved in their eating habits. Dietary choices are often a result of personal beliefs and preferences.

A survey based on self-reporting found that many rural communities adopted eating habits that provided inadequate levels of some key nutrients and most did not take supplements to correct the deficiencies. In contrast, a restaurant study found 
that the impact of a lifestyle of health and sustainability on healthy food choices is much stronger for senior diners than for non-senior diners [32].

Other research has found that adults, regardless of age, will tend to increase fruit and vegetable consumption following a diagnosis of breast, prostate, or colorectal cancer [33].

\subsubsection{Social Environment and Conditioning}

The environment can greatly impact food preferences of older adults. Those around 75 years old and older are more likely to suffer with limited mobility due to health conditions and often rely on others for food shopping and preparation [34].

In some areas, homebound seniors receive one meal per day (several fresh and frozen meals may be included in a single delivery) by communities that offer congregate meals, or meals served in community settings such as senior centers, churches, or senior housing communities. These congregate meal programs are encouraged to offer a meal at least five times per week [13, 17].

Impeded access to transportation may also be an issue for old adults, especially in rural areas where there is less public transportation. This can vary greatly due to geographic location [34].

The type of social network can also influence the food choices of individuals in our older adult population. For example, one study showed that a person that has a larger social network and lower economic status is more likely to have proper nutrition that someone who has a smaller social network and higher economic status [35]. Health and social aid can be instrumental into introducing positive change for those at risk.

\subsection{The Older Adult Perspective and the Quality of Nutritional Care}

Clinical controlled trials have shown that actively involving patients in their own nutritional care and mentoring patients could increase the patient's energy intake. A study [36] demonstrated that the patient perspective contributes to the quality of nutritional care. Studies still show that patients felt a connection between their lack of physical and psychological well-being and their inability to eat enough $[13,37]$. Both men and women experienced decreased physical strength. Lack of appetite, pain, bad taste, nausea, and early satiety were presented as the main reasons for not eating, in some studies. Within these findings, the amount of medication, especially tablets, was mentioned as a barrier to appetite, causing altered taste of food $[37,38]$.

A recent qualitative study considering enteral tube feeding in hip fracture highlighted key patient perspectives influencing nutrition support; these highlighted the need to consider patient (and/or carer) knowledge and understanding, perceived consequences and necessity of the nutritional intervention (or alternatives) in 
addition to ability to cope, attitude toward life duration, and the relative importance of tube feeding. Interestingly, three key potentially modifiable drivers were identified that were considered to facilitate or negate acceptance of tube feeding: personal perception of the situation, the value of nutrition, and perceived quality of life [39].

Another important factor to consider according to some research [39] is the food neophobia, defined as the "reluctance to eat and/or avoidance of novel foods." This may act as a barrier to the consumption of novel foods and may act as a barrier to the consumption of novel fortified foods or foods that have been specially developed for older adults. The negative impacts of this association will also be exacerbated when older adults are already at increased risk of malnutrition. Oral nutritional supplements and fortified foods may be comparable to functional foods, and food neophobia scores have been related to a reluctance to try new functional foods in adults, including older adults.

The timing of meal delivery and the presentation of the dish were considered important in some research. Patients stated that they appreciated being taken care of, especially with individually served snacks. Patients had a clear opinion about the commitment of the healthcare providers to the management of food service and stated that their attention stimulated them to eat more [40].

\subsubsection{The Role of Caregivers and Community}

The role and involvement of relatives with various aspects of nutritional care are important to patients. However, the practical role of relatives especially at discharge or leave from hospital should be considered carefully. Today, it is common that relatives are taken into practical planning of nutritional care and are taught by dietitians and nursing staff how to make food more energy dense and how to serve small portions, snacks, and supplements. Not least, urging to eat from relatives was mentioned as problematic [38]. The patients in this study described that they understood and appreciated the concern from their relatives, but at the same time, they felt they were under substantial pressure from them and felt they had no understanding toward their situation. As seen in advanced patients with cancer [41], families were concerned that their encouragement to make patients eat might become nagging and worsen the situation. Some even found that relative surging the patients to eat made them decrease nutrition intake rather than increase it. This situation should maybe be discussed with patients and relatives at leave or discharge. Fellow patients had a significant role to the patients feeling of comfort during hospitalization. A fellow patient in a futile situation seemed to have negative impact on the weak and passive patients, whereas companionship, trust, and support between fellow patients in similar situations seemed to be important and give the patient's life courage [42].

Studies such as these show the utmost importance of considering the patient's perceptions of their own nutrition and their expectations regarding the nutritional regimen prescribed by the nutritional team. This would be the first step to personally motivate each patient at nutritional risk. 


\subsection{The Effectiveness of Multidisciplinary Nutritional Care to Increase Patient Motivation}

Many studies have aimed to determine the effectiveness of a multidisciplinary intervention program on nutritional intake and of nutritional intake on nutritional status and quality of life in older patients treated for a hip fracture.

Among older adults with a hip fracture, a multidisciplinary postoperative approach of nutritional care has been associated with an increase of energy and protein intake during hospitalization, reduced malnutrition incidence, and improved home discharge rates [43]. Other works demonstrate that effective management of nutrition for those at risk will speed recovery and reduce the incidence of secondary complications and mortality, reducing nursing workload in both hospitals and community settings. Of particular interest for this chapter are studies demonstrating the positive effects of care models that combine interdisciplinary motivational care with nutrition consultation, depression management, and fall prevention in older patients with hip fracture [44]. While multidisciplinary nutrition support teams routinely include medical, nursing, dietetics, and pharmaceutical professionals, in order to consider all the important factors involved in managing nutritional care in older, multimorbid patients, these should also include psychologists and other healthcare professionals [45]. In view of the multiculturalism of patients and health professionals, the multi-professional team is recommended to have an anthropological view that will allow even more the personalization of the dietary plan and the patient's nutritional adherence.

Clearly defined responsibilities, education and training of hospital staff, cooperation between all staff groups, and the involvement of hospital management are essential measures to effectively prevent and treat malnutrition in the hospital setting [46]. In addition to consider the patient's psychological barriers that affect their nutrition, the multidisciplinary team should also consider the system's barriers and their expectations regarding the patient's nutrition plan. Some studies demonstrate that health professions' responsibilities and roles related to such care should be more formally defined. The lack of proper instructions and of assignment of responsibility means that nobody is clearly accountable for the patients' nutrition, and undernourishment is more likely to be left unrecognized and undertreated $[11,46]$. Moreover, poor cooperation among all hospital staff groups has been defined as a common barrier to good nutritional practice [47] resulting in inadequate nutrition in the chain of care.

\subsection{Summary}

In conclusion, in order to increase adherence and motivation, nutritional care recommendations must take into consideration patients' lifestyles, preferences, and psychological aspects in the nutritional care assessment, planning, intervention, and evaluation phases. Older adults and caregivers must also have an awareness of 
nutritional care basics and adequate nutritional literacy to support making informed choices about nutritional care. The possibility to understand why certain foods and fluids are to be prioritized and to choose between different options helps in moving the responsibility from the healthcare providers to the older adults, giving them the opportunity to feel to be more involved (and so more adherent and motivated) in nutritional care. In concluding, personalization is the most important point: what works with a patient is not certain to work with another, and what matters to one older adult may not be the same as what matters to another; so planning and evaluation in the multidisciplinary team should serve to consider this aspect.

\section{Take-Home Points}

- There are diverse psychological barriers and enablers that should be considered when assessing, treating, and evaluating nutrition care processes for older adults with or at risk of malnutrition.

- Despite the barriers that staff experience in day-to-day work in hospital wards to ensure adequate nutritional care for undernourished seniors, interdisciplinary work among health workers is a key enabler to meeting the complex needs of older people and motivating nutritional behavior change.

- Increasing patient motivation and adherence to nutritional care demands considering the patient's perceptions of their own nutrition, engaging them in care planning, and evaluating their expectations and experiences regarding the nutritional prescriptions recommended and enacted.

\section{References}

1. Nieuwenhuizen WF, Weenen H, Rigby P, Hetherington MM (2010) Older adults and patients in need of nutritional support: review of current treatment options and factors influencing nutritional intake. Clin Nutr 29(2):160-169

2. Bauer J, Biolo G, Cederholm T, Cesari M, Cruz-Jentoft AJ, Morley JE et al (2013) Evidencebased recommendations for optimal dietary protein intake in older people: a position paper from the PROT-AGE Study Group. J Am Med Dir Assoc 14(8):542-559

3. Volkert D, Beck AM, Cederholm T, Cruz-Jentoft A, Goisser S, Hooper L et al (2019) ESPEN guideline on clinical nutrition and hydration in geriatrics. Clin Nutr 38(1):10-47

4. Tappenden KA, Quatrara B, Parkhurst ML, Malone AM, Fanjiang G, Ziegler TR (2013) Critical role of nutrition in improving quality of care: an interdisciplinary call to action to address adult hospital malnutrition. JPEN J Parenter Enteral Nutr 37(4):482-497

5. Ten Cate D, Ettema RGA, Huisman-de Waal G, Bell JJ, Verbrugge R, Schoonhoven L et al (2020) Interventions to prevent and treat malnutrition in older adults to be carried out by nurses: a systematic review. J Clin Nurs 29(11-12):1883-1902

6. Fávaro-Moreira NC, Krausch-Hofmann S, Matthys C, Vereecken C, Vanhauwaert E, Declercq A et al (2016) Risk factors for malnutrition in older adults: a systematic review of the literature based on longitudinal data. Adv Nutr 7(3):507-522

7. de Morais C, Oliveira B, Afonso C, Lumbers M, Raats M, de Almeida MD (2013) Nutritional risk of European elderly. Eur J Clin Nutr 67(11):1215-1219 
8. van der Schueren MAEB, Lonterman-Monasch S, de Vries OJ, Danner SA, Kramer MH, Muller M (2013) Prevalence and determinants for malnutrition in geriatric outpatients. Clin Nutr 32(6):1007-1011

9. Zeanandin G, Molato O, Le Duff F, Guérin O, Hébuterne X, Schneider SM (2012) Impact of restrictive diets on the risk of undernutrition in a free-living elderly population. Clin Nutr 31(1):69-73

10. Furuta M, Komiya-Nonaka M, Akifusa S, Shimazaki Y, Adachi M, Kinoshita T et al (2013) Interrelationship of oral health status, swallowing function, nutritional status, and cognitive ability with activities of daily living in Japanese elderly people receiving home care services due to physical disabilities. Community Dent Oral Epidemiol 41(2):173-181

11. Bell J, Bauer J, Capra S, Pulle CR (2013) Barriers to nutritional intake in patients with acute hip fracture: time to treat malnutrition as a disease and food as a medicine? Can J Physiol Pharmacol 91(6):489-495

12. Bell JJ, Rossi T, Bauer JD, Capra S (2014) Developing and evaluating interventions that are applicable and relevant to inpatients and those who care for them; a multiphase, pragmatic action research approach. BMC Med Res Methodol 14:98

13. Reinders I, Wijnhoven HAH, Jyväkorpi SK, Suominen MH, Niskanen R, Bosmans JE et al (2020) Effectiveness and cost-effectiveness of personalised dietary advice aiming at increasing protein intake on physical functioning in community-dwelling older adults with lower habitual protein intake: rationale and design of the PROMISS randomised controlled trial. BMJ Open 10(11):e040637. https://doi.org/10.1136/bmjopen-2020-040637. http://europepmc.org/ abstract/MED/33444206, https://europepmc.org/articles/PMC7682452, https://europepmc. org/articles/PMC7682452?pdf=render

14. Chang M, Geirsdottir OG, Launer LJ, Gudnasson V, Visser M, Gunnarsdottir I (2020) A poor appetite or ability to eat and its association with physical function amongst communitydwelling older adults: age, gene/environment susceptibility-Reykjavik study. Eur J Ageing

15. Bell JJ, Bauer JD, Capra S, Pulle RC (2014) Multidisciplinary, multi-modal nutritional care in acute hip fracture inpatients - results of a pragmatic intervention. Clin Nutr 33(6):1101-1107

16. Bell JJ, Young AM, Hill JM, Banks MD, Comans TA, Barnes R et al (2021) Systematised, Interdisciplinary Malnutrition Program for impLementation and Evaluation delivers improved hospital nutrition care processes and patient reported experiences - an implementation study. Nutr Diet. Early view: https://doi.org/10.1111/1747-0080.12663

17. Nematy M, Hickson M, Brynes AE, Ruxton CH, Frost GS (2006) Vulnerable patients with a fractured neck of femur: nutritional status and support in hospital. J Hum Nutr Diet 19(3):209-218

18. Sánchez López AM, Moreno-Torres Herrera R, Pérez de la Cruz, AJ, Orduña Espinosa R, Medina T, López Martínez C (2005) [Malnutrition prevalence in patients admitted to a rehabilitation and orthopedic surgery hospital]. Nutr Hosp 20(2):121-130

19. Gustafsson K, Sidenvall B (2002) Food-related health perceptions and food habits among older women. J Adv Nurs 39(2):164-173

20. Brewster PW, Melrose RJ, Marquine MJ, Johnson JK, Napoles A, MacKay-Brandt A et al (2014) Life experience and demographic influences on cognitive function in older adults. Neuropsychology 28(6):846-858

21. Mowe M, Bosaeus I, Rasmussen HH, Kondrup J, Unosson M, Irtun $\varnothing$ (2006) Nutritional routines and attitudes among doctors and nurses in Scandinavia: a questionnaire based survey. Clin Nutr 25(3):524-532

22. Westergren A, Unosson M, Ohlsson O, Lorefält B, Hallberg IR (2002) Eating difficulties, assisted eating and nutritional status in elderly ( $>$ or $=65$ years) patients in hospital rehabilitation. Int J Nurs Stud 39(3):341-351

23. Grzegorczyk PB, Jones SW, Mistretta CM (1979) Age-related differences in salt taste acuity. J Gerontol 34(6):834-840

24. Savoca MR, Arcury TA, Leng X, Chen H, Bell RA, Anderson AM et al (2010) Association between dietary quality of rural older adults and self-reported food avoidance and food modification due to oral health problems. J Am Geriatr Soc 58(7):1225-1232 
25. Jung SE, Lawrence J, Hermann J, McMahon A (2020) Application of the theory of planned behavior to predict nutrition students' intention to work with older adults. J Nutr Gerontol Geriatr 39(1):44-55

26. Field K, Duizer LM (2016) Food sensory properties and the older adult. J Texture Stud 47(4):266-276

27. Lee RJ, Collins PF, Elmas K, Bell JJ (2021) Restrictive diets in older malnourished cardiac inpatients: a cross-sectional study. Nutr Diet 78:121

28. Lawrence AS (2021) The Australian Dietary Guidelines review: time to plan for wider dissemination via general practitioners. Aust J Gen Pract 50(4):252-253

29. Ghimire S, Baral BK, Pokhrel BR, Pokhrel A, Acharya A, Amatya D et al (2018) Depression, malnutrition, and health-related quality of life among Nepali older patients. BMC Geriatr 18(1):191

30. Quandt SA, McDonald J, Arcury TA, Bell RA, Vitolins MZ (2000) Nutritional self-management of elderly widows in rural communities. Gerontologist 40(1):86-96

31. Vafaei Z, Mokhtari H, Sadooghi Z, Meamar R, Chitsaz A, Moeini M (2013) Malnutrition is associated with depression in rural elderly population. J Res Med Sci 18(Suppl 1):S15-S19

32. Marshall TA, Stumbo PJ, Warren JJ, Xie XJ (2001) Inadequate nutrient intakes are common and are associated with low diet variety in rural, community-dwelling elderly. J Nutr 131(8):2192-2196

33. Kim MJ, Lee C-K, Kim W, Kim J-M (2013) Relationships between lifestyle of health and sustainability and healthy food choices for seniors. Int J Contemp Hosp Manag 25:558

34. Fitzpatrick K, Greenhalgh-Stanley N, Ver PM (2016) The impact of food deserts on food insufficiency and SNAP participation among the elderly. Am J Agric Econ 98(1):19-40

35. Holst M, Rasmussen HH, Laursen BS (2011) Can the patient perspective contribute to quality of nutritional care? Scand J Caring Sci 25(1):176-184

36. Pedersen PU (2005) Nutritional care: the effectiveness of actively involving older patients. J Clin Nurs 14(2):247-255

37. Norman K, Kirchner H, Lochs H, Pirlich M (2006) Malnutrition affects quality of life in gastroenterology patients. World J Gastroenterol 12(21):3380-3385

38. Westergren A, Ohlsson O, Hallberg IR (2001) Eating difficulties, complications and nursing interventions during a period of three months after a stroke. J Adv Nurs 35(3):416-426

39. van den Heuvel E, Newbury A, Appleton KM (2019) The psychology of Nutrition with advancing age: focus on food neophobia. Nutrients 11(1):151

40. Almdal T, Viggers L, Beck AM, Jensen K (2003) Food production and wastage in relation to nutritional intake in a general district hospital--wastage is not reduced by training the staff. Clin Nutr 22(1):47-51

41. Nourissat A, Vasson MP, Merrouche Y, Bouteloup C, Goutte M, Mille D et al (2008) Relationship between nutritional status and quality of life in patients with cancer. Eur J Cancer 44(9):1238-1242

42. Hestevik CH, Molin M, Debesay J, Bergland A, Bye A (2020) Older patients' and their family caregivers' perceptions of food, meals and nutritional care in the transition between hospital and home care: a qualitative study. BMC Nutr 6:11

43. Odlund Olin A, Koochek A, Ljungqvist O, Cederholm T (2005) Nutritional status, well-being and functional ability in frail elderly service flat residents. Eur J Clin Nutr 59(2):263-270

44. Shyu YI, Liang J, Tseng MY, Li HJ, Wu CC, Cheng HS et al (2013) Comprehensive care improves health outcomes among elderly Taiwanese patients with hip fracture. J Gerontol A Biol Sci Med Sci 68(2):188-197

45. Nightingale $\mathbf{J}$ (2010) Nutrition support teams: how they work, are set up and maintained. Frontline Gastroenterol 1(3):171-177

46. Eide HD, Halvorsen K, Almendingen K (2015) Barriers to nutritional care for the undernourished hospitalised elderly: perspectives of nurses. J Clin Nurs 24(5-6):696-706 
47. Ross LJ, Mudge AM, Young AM, Banks M (2011) Everyone's problem but nobody's job: staff perceptions and explanations for poor nutritional intake in older medical patients. Nutr Diet 68(1):41-46

\section{Recommended Reading}

Bell JJ, Bauer JD, Capra S, Pulle RC (2014) Multidisciplinary, multi-modal nutritional care in acute hip fracture inpatients - results of a pragmatic intervention. Clin Nutr 33(6):1101-1107

King PC, Barrimore SE, Pulle RC, Bell JJ (2019) "I Wouldn't Ever Want It": a qualitative evaluation of patient and caregiver perceptions toward enteral tube feeding in hip fracture inpatients. J Parenter Enter Nutr 43:526-533. https://doi.org/10.1002/jpen.1444

Reinders I, Wijnhoven HAH, Jyväkorpi SK, Suominen MH, Niskanen R, Bosmans JE et al (2020) Effectiveness and cost-effectiveness of personalised dietary advice aiming at increasing protein intake on physical functioning in community-dwelling older adults with lower habitual protein intake: rationale and design of the PROMISS randomised controlled trial. BMJ Open 10(11):e040637. https://doi.org/10.1136/bmjopen-2020-040637 http://europepmc.org/ abstract/MED/33444206, https://europepmc.org/articles/PMC7682452, https://europepmc. org/articles/PMC7682452?pdf=render

Open Access This chapter is licensed under the terms of the Creative Commons Attribution 4.0 International License (http://creativecommons.org/licenses/by/4.0/), which permits use, sharing, adaptation, distribution and reproduction in any medium or format, as long as you give appropriate credit to the original author(s) and the source, provide a link to the Creative Commons license and indicate if changes were made.

The images or other third party material in this chapter are included in the chapter's Creative Commons license, unless indicated otherwise in a credit line to the material. If material is not included in the chapter's Creative Commons license and your intended use is not permitted by statutory regulation or exceeds the permitted use, you will need to obtain permission directly from the copyright holder.

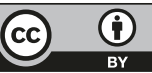

